\title{
A Competence-Oriented Approach to Subject- Matter Didactics for Software Engineering
}

\author{
http://dx.doi.org/10.3991/ijep.v5i3.4664 \\ Yvonne Sedelmaier, Dieter Landes \\ University of Applied Sciences and Arts, Coburg, Germany
}

\begin{abstract}
Instructors not only in higher education are regularly faced with the problem that they need to develop a new course or adapt an existing one to changed requirements. This is especially true for topics related to information technology (IT) due to the fast technological progress. Instructors, however, are not prepared really well for this task since they typically have a professional and educational background in areas different from pedagogy. Therefore, some sort of methodological framework to support the systematic development and refinement of courses would be highly appreciated.
\end{abstract}

This paper presents such a model, called CompetenceOriented Subject-Matter Didactics. This didactical theory builds upon several concepts from general didactics, most notably Klafki's Didactic Analysis, and combines and extends these concepts. As a proof of concept, CompetenceOriented Subject-Matter Didactics is applied to the refinement of an introductory course on information systems. This case study indicates, among other things, that this theoretical model has the potential to be applicable for course (re-)design in other domains beyond IT as well.

Index Terms-Competence-Oriented Subject-Matter Didactics; Didactic Analysis, General Didactics, Software Engineering Education, Systematic Course Design

\section{INTRODUCTION}

Instructors in higher education are regularly faced with the problem that they need to develop a new course, or to adapt an existing one to changed requirements. This is especially true for topics related to information technology (IT) since technological progress is fast in this domain. Information technology also developed into a cross-cutting discipline that affects many other areas. Therefore, IT-related topics need to be integrated into curricula of non-IT study programs as well. Unfortunately, students in such study programs are often not aware of the role of IT and, consequently, only marginally interested.

Under these constraints, it is even harder for instructors to figure out which contents should be addressed in a course, how they should be arranged, and which didactical approach might be appropriate to convey the contents to the audience in such a way that understanding is maximized. This is even more difficult for instructors who are experts in their own domain, e.g. IT, but do not have a sound background in pedagogy or didactics themselves. Often, instructors are left to their own devices and plan their courses in an ad-hoc and often only loosely systematic manner. Many didactical decisions are implicit rather than conscious choices.
This contribution presents a novel approach to a more systematic course design, based on several concepts from general didactics, such as Klafki's Didactic Analysis. This approach is supposed to work for various types of courses in diverse domains. As a proof of concept, we successfully used this approach to redesign a course on information systems in a financial management program at master level.

Before we present details on this case study on course redesign, we outline the motivation, theoretical underpinning, and core elements of our approach. A short summary and an outlook to further refinements of our approach will conclude the paper.

\section{THEORETICAL FRAMEWORKS}

\section{A. Benefit of Didactical Approaches for (Re)Designing a Course}

Subject-matter didactics aim at establishing environments that promote learning in a specific field of study. A prerequisite for any such subject-matter didactics is a better understanding of learning mechanisms. A clarification of the previous knowledge and the mental concepts that students bring into a course at its outset is the basis to adapt the course to students' real needs. In case of a mismatch between students' requirements and the didactical concept, learning remains on a very simple level and will not foster relevant competencies. Course design encompasses various issues which have to be decided upon and need to be coordinated, such as the following questions:

- Which contents should be learned and why?

- How can instructors promote learning?

- Which methods support students' learning?

Didactics facilitate these decisions and help creating good learning environments by systematically analyzing the specific learning situation and putting decisions on a sound theoretical basis.

\section{B. Improving Course Designs by Didactic Analysis and Supplementary Approaches}

The research reported here is part of EVELIN (Experimental Improvement of Learning Software Engineering), a project that aims at improving software engineering education through a comprehensive research design [1]. In this context, suitable didactical approaches are adapted to the specific needs of software engineering education [2], [3], [4], [5], [6], [7] in order to develop a subject-matter didactics for this domain.

In Germany, pedagogical theories have a longstanding tradition of several hundred years and are heavily 
influenced by events and the mindset at the time of their development. Pedagogical theories mirror the specific problems and challenges of the society at their date of origin. Didactical theories make general and universally valid statements about learning, learning processes, and determinants which influence these processes. As a consequence, pedagogical and didactical theories must be put into practice. In addition, they must be adapted to the actual needs and requirements of the particular situation and the specific subject to which they are applied. In general, it is not possible to take a pedagogical framework off the shelf and use it without further refinement or adaptation. General pedagogical and didactical theories leave ample scope for interpretation which has to be filled.

Klafki's Didactic Analysis [8-10] is a well-known approach in general didactics. In this paper, this approach is utilized, adapted, and supplemented by other widespread didactical concepts, e.g. [11], in order to put didactical decisions on a sound basis and to develop a learning environment which satisfies students' needs. Furthermore, various other well-known didactical approaches from general didactics can be used as theoretical frameworks for (re-) designing courses in higher education. In this paper, we show how they can be applied to everyday education and combine it with elements from Didactic Analysis.

The resulting approach can be viewed as an application of general didactics as well as an extension and operationalization of Didactic Analysis that is targeting various courses in informatics on bachelor and master level, and for informatics majors as well as minors.

\section{Klafki's Bildung-Centered Approach to Didactics}

Each theory in general didactics presupposes a theoretical basis that helps to adapt it to specific learning situations.

\section{1) Klafki's Theory of Education}

Like many others pedagogical theories, Klafki's theory of education has a fairly philosophical and abstract underpinning. Klafki [9] is a representative of human science pedagogy (Geisteswissenschaftliche Pädagogik) and, at a later point of time, of critical constructive theory of education (kritisch-konstruktive Didaktik). Klafki systematically analyzed the contents and goals of teaching and learning processes. He viewed didactics as an instrument to clarify contents and aims of teaching. Thus, he prioritized didactics over methodological questions (primacy of didactics). This means that methodological aspects follow didactics because they depend on goaloriented didactical decisions. Methods without didactical considerations are not helpful.

The concept of Categorical Education (Kategoriale Bildung) is at the core of Klafki's Bildung-Centered Approach to Didactics which merges "formal education" and "material education". The former focus on methods of learning and thinking and on personal soft skills, while the latter covers a comprehensive range of encyclopedic knowledge that is required to make a person educated. Formal education concentrates on the subject, while material education focuses on the objects that need to be learned.

Education should foster categorical education issues in both aspects. One core element is "Exemplar Approach" in the sense of Bruner's concept of "learning by discovery" [12] which means that pupils should learn things by examples which they can transfer to a more general context. The programming language ALGOL 60, for instance, might be taught with the expectation that students are enabled to familiarize themselves with future procedural programming languages on their own, simply because they understand ALGOL's basic concepts and can transfer them to, e.g., the programming language C. In this context, Klafki's approach helps to take decisions on the content of education as well as on the educational substance of content. Contents which are taught should exhibit current and future significance for students.

Klafki offers Didactic Analysis as an approach to decide on the content of education (Bildungsinhalt) on the one hand, and on the substance of content (Bildungsgehalt) on the other hand.

\section{2) Klafki's Didactic Analysis}

Didactic Analysis is a pedagogical instrument which is used in teacher education for about four decades.

"The core questions of the didactic analysis refer to the (2) current and the (3) future significance of the chosen content for the students, which means that teachers should reflect on educational substance of the mandatory curriculum. Question 1 focuses on the aforementioned exemplarity of the chosen topic, question 4 on its structuredness, and question 5 on the accessibility of the topic (=methodical aspects of teaching)." [13]

This quote refers to the five core questions in Klafki's Didactic Analysis:

"I. What wider or general sense or reality do these contents exemplify and open up to the learner? What basic phenomenon or fundamental principle, what law, criterion, problem, method, technique, or attitude can be grasped by dealing with these contents as 'examples?'

$[\ldots]$

II. What significance does the content in question, or the experience, knowledge, ability or skill to be acquired through this topic already possess in the minds of the children in my class? What significance should it have from a pedagogical point of view?

$[\ldots]$

III. What constitutes the topic's significance for the children's future?

$[\ldots]$

IV. How is the content structured (which has been placed in a specifically pedagogical perspective by questions I, II and III)? 


\section{$[\ldots]$}

V. What are the special cases, phenomena, situations, experiments, persons, elements of aesthetic experience, and so forth, in terms of which the structure of the content in question can become interesting, stimulating, approachable, conceivable, or vivid for children of the stage of development of this class." [10]

These questions are related and intertwined with each other. In their entirety, they provide a complete picture of a course.

\section{3) Evaluation of Klafki's Approach}

Klafki's Didactic Analysis is a methodological framework that is intended to support the systematic analysis of courses. The resulting prioritization of contents allows focusing on particular issues in such a way that the covered topics become more easily understandable for the intended target audience.

Initially, Didactic Analysis neglected methodological aspects completely.

Furthermore, Klafki's general framework needs to be supplemented by additional didactical approaches. While Klafki's approach clarifies the educational content in general, it lacks support for choosing specific methods or media. Even though Klafki extended Didactic Analysis in this respect [14], it still falls short of being an applicable framework for planning single lessons. In order to close the remaining gap, we combined Didactic Analysis with elements of other didactical approaches such as [11]. Consequently, the resulting framework is a tool to decide on relevant content for a particular target audience, but also on the ways which are best suited for teaching and learning these contents.

Moreover, Klafki's approach considers learning conditions and influencing factors only implicitly.

Nevertheless, it does not seem to be helpful to choose some methods or media without knowing the intended learning outcomes. Therefore, the primacy of didactics from Klafki's theory can be utilized in CompetenceOriented Subject-Matter Didactics (see sec. III).

Furthermore, thinking about the educational substance and the significance of the chosen content seems to be worthwhile for teachers and lecturers.

\section{The Learning-Centered Approach to General Didactics (Berlin Model)}

Paul Heimann, one of Klafki's scholars, devised the Berlin Model as a more practical approach for every-day use in education. Heimann's Berlin Model aims at enabling teachers to analyze their lessons on a purely empirical and objective basis. The Berlin Model was developed to make educational decisions more transparent and to assist teachers in considering as many factors as possible in planning their lessons. Other than Klafki's "developmental education theory" (Bildungstheoretische Didaktik), the Berlin Model of Lesson Planning [11] does not think in purely idealistic terms of human science pedagogy (Geisteswissenschaftliche Pädagogik), but aims at supporting practical decisions of teachers by taking all planning-relevant factors influencing teaching and learning into account.

In the Learning-Centered Approach, the focus shifts from "Bildung" (Klafki) towards learning. Didactics do not focus on personality any longer, but rather on being

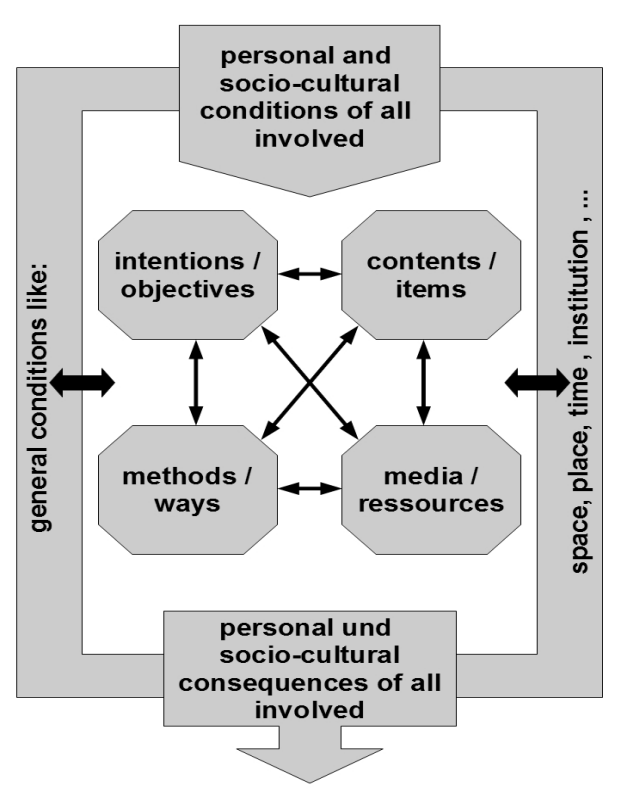

Figure 1. Berlin Model

(http://commons.wikimedia.org/wiki/File:BerlinerModellE N.jpg\#mediaviewer/File:BerlinerModellEN.jpg)

part of the society. Therefore, cultural aspects become less important in favor of contents of learning and information. Now teaching with emphasis of effective organization of learning processes becomes increasingly relevant for didactics. This change of mind went along with a more practical view on didactics.

Heimann's scholar Schulz distinguished four fields of decision making (see fig. 1):

- Intentions;

- Themes, topics;

- Methods;

- Media.

These areas of decision are constrained by two types of conditions: socio-cultural and individual conditions of students.

These aspects offer a comprehensive view on interrelationships of learning processes. Therefore, this approach seems to be quite appropriate to analyze and plan courses since it is general enough to analyze nearly all kinds of lessons, independent of the subject.

Yet, in contrast to most pedagogical theories, the learning-centered approach to general didactics lacks an underlying learning theory, i.e. neither offers any specific definition for learning, nor builds on specific assumptions of how learning works [15].

\section{E. The Hamburg Model of Lesson-Planning (Hamburger Modell)}

Schulz revised the Berlin Model in order to emphasize teachers' critical reasoning on the societal dimension of schooling. By then, Schulz had moved from Berlin to Hamburg. Thus, the resulting model was called Hamburg Model [16].

Schulz emphasized three main educational objectives: competence, autonomy, and solidarity. As a consequence, tuition needs experience of theme, of feel, and of social 
interaction. These aspects reflect Ruth Cohn's ThemeCentered Interaction (TCI) by balancing "I" (individual subject), "it" (theme), and "we" (group). [17]:

Schulz established five categories for lesson planning

- Criteria of planning with focus on teaching, e.g. action-orientation;

- Four areas of decision making and two areas of conditions according to the Berlin Model;

- Didactical activities, such as advising, evaluating, analyzing, planning, realizing, and executing and acting cooperatively;

- Fundamental thoughts on lesson planning. To achieve the aforementioned three main goals of education, namely competence, autonomy, and solidarity, learners have to experience themes in three aspects: things, feelings, and social interaction;

- Levels of planning.

The latter relies on different stages of lesson planning, namely prospective planning, outline planning, process planning, and planning corrections. Prospective planning has an extended temporal perspective, e.g. a term, a calendar year, or a school year. Outline planning focuses on individual teaching units. Process planning arranges topics in time. Planning corrections allow teachers to react to unexpected situations during the course.

All in all, the Hamburg Model expands the Berlin Model's decision and condition areas with societal issues. This introduces a normative component into the theory, an aspect which was widely criticized.

Furthermore, a more theoretical framework is built around these fields by defining the aforementioned five categories of lesson planning. These categories add new aspects and questions which should be considered when thinking about didactics.

\section{F. Critical Constructive Approach to Didactics}

Under the impression of the German student protest movement in the late 1960s, Klafki elaborated his model into the Perspective Scheme of Lesson Planning. His concept of education renewed the idea of general education by relating it to the Critical Theory of Society of the Frankfurt School (Habermas, Horkheimer). Klafki focuses on emancipation as a central goal of education. He also defined Key Problems of the Modern world [18] such as peace, environment, unequal distribution of wealth, (un-)employment, relationship between generations and between men and women. Educational contents should reflect these key problems.

New concepts of Didactic Analysis include methodological aspects [14] and, in his later work [10], even Klafki highlights the connection between intentionoriented and methodological aspects of planning a course.

In his new approach, learning becomes more interactive instead of only focusing on contents.

Still, Klafki's approach remains quite static because it focuses on analyzing structures after all. Dynamic elements such as process planning remain implicit only.

\section{A Novel Approach to Plan, Structure,}

INITIATE, ACOMPANY, AND EVALUATE LEARNING PROCESSES (COMPETENCE-ORIENTED SUBJECT-MATTER DIDACTICS)

Klafki's Didactic Analysis for analyzing and planning curricula is based on five key questions. Our approach takes Klafki's Didactic Analysis as a starting point and adapts it to our specific needs, e.g., for analyzing a course such as "Information and Communication Systems".

We extend and combine Klafki's approach of Didactic Analysis with elements from other educational theories, in particular the Berlin Model and the Hamburg Model (see sec. II).

This results in a so-called Competence-Oriented Subject-Matter Didactics (see fig. 2) which contains elements from the aforementioned didactical theories supplemented by summative and formative evaluation [19] issues.

As a starting point, we use Klafki's Didactic Analysis to clarify the educational content and substance. Competence-Oriented Subject-Matter Didactics follows Klafki's primacy of didactics. This means that the educational objectives are defined at the beginning of the planning process and serve as compass for the further planning steps.

Competence-Oriented Subject-Matter Didactics aims at putting students into the position to transfer their theoretical knowledge into usable action knowledge for being able to solve complex problems in their daily business. That is, our primary educational goal is acquiring and exercising competencies in line with Weinert's [20] or Hartig's [21] understanding of the term "competence" (see sec. III A). These competencies obtain a specific characteristic in the context of a subject-matter, in particular informatics and software engineering [22].

The Berlin Model's two condition areas are added to Competence-Oriented Subject-Matter Didactics to analyze the constraints of the planned learning processes.

The following planning levels, namely prospective, outline, and process planning are inspired by the corresponding elements of the Hamburg Model. The four decision areas of the Berlin Model are incorporated into these planning steps. Prospective planning focuses on content and structural aspects which are specified in outline planning. The latter also introduces methodological aspects. Process planning emphasizes methods and media which are used in a single specific lesson. The level of detail concerning methods and media increases in parallel with the level of detail in operationalising educational objectives.

After planning a learning situation from general to detail, realization takes place. Within this phase, planning correction as mentioned in the Hamburg Model is necessary. In addition, elements from constructivist didactics are used, e.g. participant orientation [23]. Hunt describes this as "reading" and „flexing" [24]: Reading means attentively observing students, while flexing concerns reacting on recognized requirements and needs. This generates an iterative process of adapting teaching and learning.

In order to improve learning processes the phase "evaluation" completes Competence-Oriented Subject- 
Matter Didactics. The aforementioned didactical theories neglect evaluation in unison.

Evaluation in Competence-Oriented Subject-Matter Didactics operates on two levels, namely summative and formative evaluation [19]. In this didactical concept, evaluation is concerned with the assessment of students' competencies by trying to find out which competencies they developed, e.g., by writing an exam. Furthermore, evaluation focuses on the effectiveness of the used didactical approach, especially the chosen methods and media. Therefore, students' competence developments as a whole are the basis to draw conclusions with respect to the didactical approach. Software Engineering Competency Assessment Tool (SECAT) as an evaluation tool rests on a sound theoretical basis and initiates further refinement of the didactical approach in order to provide a subject-matter didactics [7].

\section{A. Definition of Terms and Learning Theory of Competence-Oriented Subject-Matter Didactics}

From a normative point of view, CompetenceOriented Subject-Matter Didactics assumes that learning process should foster students' competencies. Competencies constitute the capability to cope with complex and new situations and also presuppose additional skills, which are often subdivided into social, personal, and methodological competence [25-27].

In this paper, the term "competence" is not used for factual or technical knowledge since, according to Weinert [20] (p. 35), a "skill is an ability to perform complex motor and/or cognitive acts with ease, precision, and adaptability to changing conditions". Following this view, neither soft skills, nor factual knowledge in isolation are competencies. Competencies can only come into existence when both interact: "Competence" presupposes technical or factual knowledge and also soft skills. Moreover, competence encompasses the context, emotional elements, and also possesses an ethical, normative component. Competence enables individuals to analyze complex and new situations, to find creative potential solutions, and to decide on one way of action, in due consideration of causes and consequences. Competence also includes the willingness and motivation to act autonomously and based on self-initiative after a cognitive analysis of a situation. Competence-Oriented Subject-Matter Didactics distinguishes context-sensitive soft skills, generic soft skills, and factual knowledge [3], all of which are specific to the domain of software engineering.

As mentioned above, university education should foster students' competencies. But neither are there clear causeeffect-relationships, nor can competency be traced back to a single didactical approach or method. Nonetheless, higher education should address competencies and create environments that promote students' competencies in accordance with constructivist didactics.

Social constructivism assumes that each student builds his or her individual model of reality. Successful learning presumes that the new topics have to be added to already existing mental structures. As a consequence, students acquire a greater responsibility for their own learning processes and outcomes. Conversely, instructors turn into coaches whose main role is facilitating learning by creating suitable learning environments and situations. As a consequence, instructors can no longer control or determine learning processes in detail, but only influence them marginally by initiating and accompanying them.

\section{B. Key Questions of Competence-Oriented Subject- Matter Didactics}

The starting point for developing a didactical concept is the definition of target competencies. Once this is accomplished, the core questions we use for analyzing, planning, and realizing learning situations are the following (for their interrelationships see figure 2):

\section{1) Planning \& Structuring}

- Societal, general, and personal conditions: What are the basic conditions? Which organizational restrictions do exist for this course?

- Substance of Content: What are the main ideas and goals of the course (general goals)? (Primacy of Didactics)

- How is the topic transformed into a key question?

- Current and future significance: Why should students in a particular study program cope with a particular topic? Where in their past or future lives did or will students have contact to these subjects? What exactly is the educational merit and substance of the issue?

According to the Hamburg Model, planning happens in different stages, namely prospective planning, outline planning, process planning, and planning corrections.

\section{a) Prospective planning}

Prospective planning deals with an overall perspective on content and structure and has an extended temporal scope, e.g. a term, a calendar year, or a school year.

- What is a useful structure of contents?

- How does the background of students influence learning? Do students have previous knowledge? Are there wrong assumptions or misconceptions?

\section{b) Outline planning}

Outline planning happens on a more detailed and more limited level. Outline planning focuses on individual teaching units by asking questions such as the following:

How is the subject accessed? How can students acquire interest for the subject? How can learning situations address objects, feelings, and social experiences? Is an inductive way of learning more appropriate than a deductive one? Is the concept based on an inductive or deductive way of learning? Does it bring students from general to detailed aspects or vice versa? Should students learn some examples which are exemplary for the whole topic (learning by example) [28] or should they deduce practical knowledge from general regularities? Should they transfer general laws to real world problems by themselves? Access to the subject is also determined by the level of activation that instructors enforce, i.e. do they want students to participate actively in the learning process or do they apply instructive ways of teaching? An additional question is whether the subject is approached from a problem or from a solution. Which didactical principles [29] are recognized and are they tailored to the goals? What about repeating contents? When and how? 


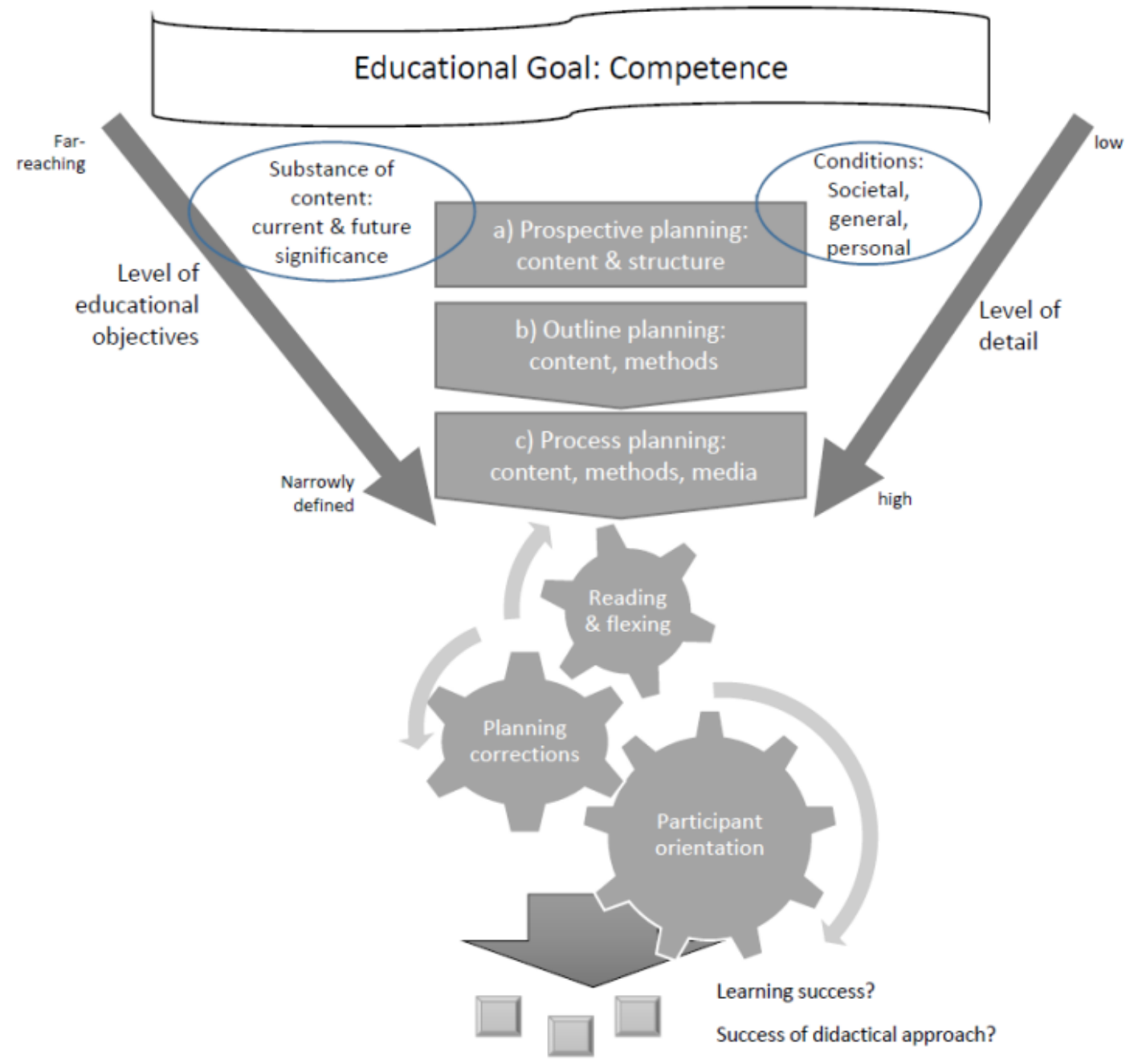

Figure 2. Competence-Oriented Subject-Matter Didactics

\section{c) Process Planning}

Process planning is concerned with arranging topics on a time line, i.e. putting them into a proper temporal sequence.

- How are the educational objectives operationalised to intended learning outcomes?

- Which methodological approach shall be taken for a specific topic under specific circumstances considering the educational objectives? Which methods and media are chosen and why?

\section{2) Realization}

Planning corrections allow teachers to react to unexpected situations during the course. This leads to questions such as:

How and what type of information do instructors collect regularly in order to stay current with students' learning processes and to provide feedback? How do they recognize if students understand the matter, where do they have misconceptions, and what did surprise them?
Adapting microdidactical elements during the lesson is based on the didactical principle of participant orientation ("Teilnehmerorientierung") [29] which is perfectly in line with constructivist didactics. Hunt [24] describes it as "reading" and ,flexing". Reading means attentively observing students, while flexing concerns reacting on recognized requirements and needs. This results in an iterative process of adapting teaching and learning.

\section{3) Evaluation}

How are students' competencies assessed? There should be some kind of measurement if they achieved the educational objectives and fostered their competencies.

Furthermore, there should be an evaluation of the applied didactical approach to improve learning continuously. Did the applied didactical approach work well? Why or why not?

We devised Software Engineering Competence Assessment Tool (SECAT) in order to measure the gain in students' competencies as a basis for evaluating didactical approaches [7]. 


\section{Case Study: ApPlying Competence-ORIENTED SUBJECT-MATTER DIDACTICS TO AN INFORMATION SYSTEMS COURSE}

As a representative case, we applied CompetenceOriented Subject-Matter Didactics to a course "Information and Communication Systems" in a master program on Financial Management. As a baseline, we use the shape of the course as it was held in the winter term $2012 / 2013$ and refer to changes we introduced in the winter terms of 2013/2014 and 2014/2015.

The master program on Financial Management is not IT-related, but rather focuses clearly on economic issues. An additional, specific challenge arises from the fact that it is an international study program. Thus, there are different geographical and professional cultures, and the mindsets of economists and software engineers or IT specialists have to be aligned, even more so since this is not just a requirement for a university course: Also in professional practice, the two worlds need to meet each other. Software engineers or IT specialists have to cooperate with economists: Economists express what they expect from software, and software engineers develop software by relying on this information. Unfortunately, in practice there are various challenges when computer scientists and economic persons work together.

Below, some of the challenges of teaching information systems to business administration students will be discussed in more detail, and conclusions for Competence-Oriented Subject-Matter Didactics will be drawn from this analysis. There will also be an outline of how didactical approaches can be used to analyze and design such a course in a goal-oriented manner, for instance by clarifying the reasons for, e.g., methodological decisions.

\section{A. Educational Goal for Information and Communication Systems}

The objective of the course is to generate an understanding of the role of information systems for an enterprise in general and in financial management in particular. Participants should understand general concepts of information systems and get an idea of how IT works. Participants should gain a deeper understanding of basic technologies of information systems and their interrelationships, e.g. networks or databases. Furthermore, participants should be able to understand and even apply selected techniques presented in the course such as business process or use case modeling for requirements analysis. At the end of the course, students should recognize the main benefits and risks of information systems for their professional career.

\section{B. Societal, General, Personal Conditions}

The MBA program Financial Management at Coburg University presupposes a bachelor degree in business administration plus work experience in this field. The program is designed for an international audience. As a consequence, an audience of 20 to 40 people typically originates from more than a dozen different nations. Therefore, the acquaintance of such a heterogeneous audience with IT in general and information systems in particular also varies greatly: Some students worked as consultants for ERP systems for several years, while others do not have any knowledge on IT systems beyond typical text processing or presentation software.
Due to their different origins, also cultural differences within the group need to be taken into account. In addition, English is the least common denominator for communication within the group and with instructors although it is the native language of only a small minority of students, if any.

Besides an introduction to ERP systems, Information and Communication Systems is the only course in the curriculum with a somewhat technical focus. Information and Communication Systems has two contact hours per week over a term of 15 weeks; its workload is equivalent to 2.5 credit points. At the end of the term, there is a written examination of 45 minutes.

The general settings for the course did not change over the last few years.

\section{Substance of Content}

This section aims at characterizing the main ideas and goals as well as transforming the subject matter into key questions (see section III.B.1).

The key question for the course can be phrased as "Which benefits do information systems provide for me in my job after finishing the Financial Management program?". This general theme can be broken down into more specific questions, such as:

- How do information systems work?

This touches upon the required technologies (databases, communication technology), but also refers to software architectures of information systems (client/server, multi-tier).

- How are information systems used in practice?

This question leads to typical categories of information systems (B2B / B2C / Computer-supported cooperative work, Transaction processing / Management information / Decision support / Executive information systems).

- What are limits and risks in using information systems and how can I handle them?

This encompasses aspects of IT security and privacy, including hazards such as malicious software and countermeasures (security updates, antivirus software, firewalls).

- Which role do I play during the selection / development of a suitable information system?

Although non-IT persons will not build IT systems by themselves, they are still involved in the software lifecycle; particularly requirements analysis and (acceptance) testing are relevant for non-IT persons. Furthermore, the "interfaces" between non-IT persons and software engineers need to be clarified, in particular with respect to the information on processes and data that must be conveyed from the application domain to the development organization. This is also meant to provide a clearer picture of the different mindsets of non-IT and IT persons.

Although the key questions did not change with respect to the situation before applying CompetenceOriented Subject-Matter Didactics, they had not been expressed so explicitly. In our baseline, a written syllabus was primarily focusing on contents rather than intention of the course. 


\section{Current and Future Significance}

Characterizing the significance aims at identifying areas where the subject matter has been or will be relevant for the target audience (see section III.B.1). These issues touch upon why students should get involved in the subject and which benefit they can expect from doing so.

Typically, all Financial Management students have some acquaintance with text processing or presentation software, and all of them are familiar with using the internet, both for private purposes and during their bachelor education or in the workplace.

Yet, only few of them possess a deeper knowledge of the underlying technology. For instance, they know that IP addresses are important with respect to the internet, but they do not really understand why. Basic technological knowledge will help them to gain a better and more coherent picture of how different technologies fit together. Consequently, students will be better prepared to cope with unexpected things in complex situations in their everyday business.

Furthermore, students tend to use the internet somewhat airily. Deeper insights into security issues will increase their awareness of potential risks and consequences of neglecting security aspects. As a consequence, they will also act more cautiously, for instance when they can distinguish a secure URL from an unsecure one or use encrypted communication channels via HTTPS.

Finally, a better understanding of the technological potential in IT leads to a change in perspective. Originally, students tend to assume that they have to take software as it is: If there is an appropriate piece of software, it can be used; if there is none, there is nothing that can be done about it. This attitude is replaced by the insight that, especially in a professional context, software might be built to their needs. Yet, this presupposes that they are able to express their requirements in a way that can be understood by other disciplines, namely by software engineers. Cooperation with other disciplines is inevitable.

\section{E. Prospective Planning}

Prospective planning aims at clarifying which contents are relevant for the audience, given the general substance of the matter.

Prospective planning is heavily constrained by some of the context conditions, namely the professional background of the participants as well as their previous knowledge. In order to clarify these issues further it is also desirable to uncover misconceptions that participants might have with respect to some of the material to be covered in the course.

In order to gain insight into these issues, we asked participants to introduce themselves in a short presentation, highlighting their geographical origin, their professional experience (including higher education), their knowledge on IT, and their expectations for the course. In particular in the winter term $2014 / 2015$, this clearly showed that the previous knowledge of participants with respect to IT is fairly poor, the audience is extremely heterogeneous in terms of professional experience and studies, and misconceptions with regard to the goals and contents of the course were pretty common.
As a consequence, we tried to straighten out these misconceptions by highlighting which expectations might be fulfilled in the course, and which would not.

In parallel, contents needed to be rearranged and additional, more basic issues needed to be introduced in order to cope with the low level of previous knowledge. Doing so is an instance of participant-orientation.

An important issue is finding an appropriate alignment of topics (see section III.B.1). Competence-Oriented Subject-Matter Didactics implies a different access to the subject matter based on more realistic case studies and examples. In the baseline, contents were often presented instructively by first explaining technologies and then showing their potential usages.

This is now somewhat reversed. Primary emphasis is now put on specific goals that need to be achieved by using an information system, and then deriving what technological issues are required for meeting these goals. For instance, the point that information systems should be distributed led to the required communication technologies, e.g. TCP/IP or HTTP, and to software architectures such as client/server or multi-tier. Distributed information systems that exchange potentially confidential information over the internet then lead to an understanding of the reasons why a VPN connection might be required to safeguard information, and why it might be wise to prefer a slower, but more secure connection over of a fast, but insecure one.

\section{F. Outline Planning}

Outline planning is concerned with planning how a particular subject will be accessed, in particular in order to engage students in the subject since they find it interesting in some way (see section II.B.1).

In our baseline, contents were presented in a somewhat abstract manner which was easily intelligible for those students that were already somewhat familiar to the matter. "Newcomers", however, could hardly imagine what the presented material meant precisely. As an instance of active learning, students were required to investigate a technological aspect in teams of two or three students. Findings were reported back to their classmates in presentations of roughly 15 minutes each, and written reports of 5 to 10 pages were prepared for each subject and provided on a file server. This approach, however, fell short of generating a broader understanding - each group only understood their own topic well, but often failed to see the point in other topics.

Thus, Competence-Oriented Subject-Matter Didactics required changing that approach in order to live up to the key questions raised. Emphasis moved away from theoretical technical knowledge and now lies on the context of information systems in an economic world. The subject matter is transferred closer to students' reality, thus making it more accessible and more interesting. By and large, the main emphasis was put on creating a better understanding, e.g. of how computer networks and the internet operate, which roles particular networks play in this context, etc.

To that end, we used three case studies that showed how information systems were used in a realistic setting. Thus, technical content was linked to the students' economic background and their prior knowledge. As a side effect, this approach made information systems more 
familiar to students and less technical; it became clearer to students why it could be helpful to understand security issues and types of connections.

In a similar vein, additional topics were conveyed using close-to-life examples from their world. For instance, different categories of information systems, such as transaction processing or decision support systems, were made more tangible by discussing how a company such as Amazon might use them.

Furthermore, Competence-Oriented Subject-Matter Didactics revealed that the choice and order of presentation of issues was not ideal to meet the key questions. Therefore, we slightly adapted them and put considerably less emphasis on databases. Instead, we put more stress on describing required or offered services of information systems, thus laying the basis for expressing requirements as use cases [1].

Awareness for IT security was raised with questions such as "How can I make sure my money is safe when I do internet banking?", "How can I recognize phishing mails?", or "Under which conditions should I enter my banking credentials?". Again, these questions are close enough to students' reality to raise interest.

As it turned out, this approach of transferring the technical content to scenarios that are familiar to the students worked well in stimulating lively discussions in which almost everybody in the course got involved.

\section{G. Process Planning}

Process planning aims at identifying the didactical methods that are appropriate to achieve teaching and learning goals for a course. In general, this includes the formulation of tasks that students need to work on, but also considerations of how a link to the topics discussed in the last class could be established.

It was already mentioned above that contents were often presented instructively in the baseline. Additionally, distinct technological topics had to be investigated and presented in a group assignment.

Competence-Oriented Subject-Matter Didactics indicated that this approach was not completely convincing since students had a tendency to remain passive instead of getting actively involved.

Therefore, the methodology of teaching changed in the current term. Now, the instructor leads students through a process of building up a comprehensive picture of internet. The structure of the internet constitutes the starting point for this process; afterwards information is added on how communication over the internet works, and then the transport of data through the internet is explained. Thus, technological challenges and obstacles became obvious for students. As a consequence, they developed an awareness and understanding for security aspects and how they work. All this was developed in a joint effort in lively discussions which were guided by the instructor and involved almost all of the students. Now, they developed interest and asked questions by themselves without being expressly urged to do so.

The changes in emphasis and structure of contents combined with new real-world case studies led to other methodological decisions: the students learned a smaller share of material by hearing theoretical knowledge as before in lectures, but an increasing portion by working together in small groups and plenary discussions.
As one characteristic example, occupation with security aspects was also turned from a group assignment into a discussion. Why did we do that? In the baseline, a group work based on problem-based learning was employed to give students an understanding of security aspects when using the internet. Even though they were provided with hints to literature, it turned out to be quite difficult for them to summarize the relevant information and present it to their peer students.

Currently, group assignments were still used, but their character and mission changed significantly. As an initial group assignment, students have to work on a case study in small groups of approximately 7 students. In this group work, students need to solve a given problem in the context of the case study, reflect on possible solutions, and finally make a proposal for a possible solution on a flipchart or an overhead slide. This was different to the baseline course where we tended to start out from a solution, but students occasionally did not even see the problem that was to be solved. Due to CompetenceOriented Subject-Matter Didactics, the methodology was inverted and now starts out from a problem that has to be solved; only in a second step a solution is worked out. This approach can be allocated to problem-based learning [30] and was used once at the beginning of the term.

The initial case study was referenced as a running example during the whole term. So, we achieved a common example in a heterogeneous group of students. This case study also initiated certain group dynamics. Students adopted an active behavior over the whole term because they were encouraged to do so from the first class on. By applying more learner-activating methods the course became livelier and students took part actively. They asked more and frequently also unsolicited questions and were encouraged to think about the theme. This also led to more interaction within the class and to technical discussions among the students.

Competence-Oriented Subject-Matter Didactics also showed that the heterogeneity of the audience was only taken into account insufficiently in the baseline course. Problem-based group assignments also address this issue. Since these assignments are treated in small peer groups, students take courage to ask also seemingly stupid questions to their peers. If there are knowledgeable colleagues in the group, the question can be answered on the spot; if not, the question apparently is not so stupid, and therefore one does not make a fool of oneself if the instructor is asked for help. In a certain sense, this brings in an additional aspect that can be allocated to peer instruction since there is a direct transfer of knowledge among students.

In summary, more learner-activating methods for the student group as a whole were applied continuously over the complete term instead of using problem-based learning approaches in smaller groups. The latter was employed only once at the beginning of the term.

\section{H. Realization}

An important aspect in realizing the didactical concept is the flexible reaction to difficulties that students encounter. As a prerequisite, instructors need to get aware of difficulties and misconceptions. This can be accomplished by asking questions in order to get impression of the degree of understanding from the given 
answers, and observing and coaching students while they were working on a task assignment in class.

In the particular course, it became apparent that students did not get a clear picture of why network protocols are needed in computer networks. We tackled this by addressing this point again, using a different and more accessible scenario.

In the last course, we made the additional observations that students stayed quite passive and hardly took part in the lessons actively. To involve students and increase their motivation to play a more active role in the lesson we pursued two main approaches:

First, students were given clear and precisely written tasks at the beginning of group assignments. This should give them more confidence in doing the right thing by giving them a better idea of instructors' expectations.

Second, group work was split into a two-step process: In the first step students assemble in small groups of 5 persons to discuss a specific topic. Then, in a second step, instructors brought together 2 to 3 groups which had worked on the same tasks to merge their results to one result. This yields several good results because none of the groups developed a complete solution alone, but rather brought in just some part of an overall solution while neglecting some aspects that other groups brought in.

\section{SUMMARY AND OUTLOOK}

The application of didactical knowledge leads to a better understanding of learning and allows instructors to match specific learning environment and methods with students' requirements. The paper provides evidence which was gained from applying didactical approaches as a scientific discipline [31]. It describes the changes and improvements which are caused and triggered by applying didactical concepts systematically.

In particular, we used well-known elements from general didactics and combined and extended them, giving rise to a novel approach called CompetenceOriented Subject-Matter Didactics. The latter constitutes a scientific approach to plan and design a course in engineering education. In particular, this approach builds on Klafki's Didactic Analysis. Yet, Klafki's Didactic Analysis cannot be used right out of the box, but rather needs to be operationalised to be usable in practice, also taking influence from other models, such as the Berlin Model and the Hamburg Model, into account.

The resulting approach is applied successfully to a representative example, namely a course on information and communication systems in an MBA program. This shows how approaches from general didactics as a discipline in its own right support analyzing, improving, and further developing higher education in computer sciences. It helps instructors to ground their didactical decisions on a solid pedagogical underpinning and shows a way how instructors can benefit from thinking about didactics.

We applied Competence-Oriented Subject-Matter Didactics to several courses in higher education of informatics. Although small adaptions might be required for other domains, Competence-Oriented Subject-Matter Didactics seems to be general and beneficial enough to be widely applicable.

\section{REFERENCES}

[1] Y. Sedelmaier and D. Landes, "A Research Agenda for Identifying and Developing Required Competencies in Software Engineering," International Journal of Engineering Pedagogy (iJEP), vol. 3, no. 2, pp. 30-35, 2013. http://dx.doi.org/10.3991/ijep.v3i2.2448

[2] Y. Sedelmaier and D. Landes, "A Multi-Level Didactical Approach to Build up Competencies in Requirements Engineering," in 8th International Workshop on Requirements Engineering Education \& Training (REET 2014): CEUR Workshop Proceedings vol. 1217, 2014, pp. 26-34.

[3] Y. Sedelmaier and D. Landes, "Software Engineering Body of Skills," in Global Engineering Education Conference (EDUCON): IEEE, 2014, pp. 395-401.

[4] Y. Sedelmaier and D. Landes, "Using Business Process Models to Foster Competencies in Requirements Engineering," in 27th International Conference on Software Engineering Education and Training (CSEE\&T), 2014, pp. 13-22. http://dx.doi.org/10.1109/cseet.2014.6816776

[5] Y. Sedelmaier and D. Landes, "Practicing Soft Skills in Software Engineering," in Overcoming Challenges in Software Engineering Education, L. Yu, Ed.: IGI Global, 2014, pp. 161-179. http://dx.doi.org/10.4018/978-1-4666-5800-4.ch009

[6] D. Landes, Y. Sedelmaier, V. Pfeiffer, J. Mottok, and G. Hagel, "Learning and teaching software process models," in Global Engineering Education Conference (EDUCON), 2012, pp. 11531160. http://dx.doi.org/10.1109/educon.2012.6201191

[7] Y. Sedelmaier and D. Landes, "A Multi-Perspective Framework for Evaluating Software Engineering Education by Assessing Students' Competencies: SECAT - A Software Engineering Competency Assessment Tool," in 44th Frontiers in Education (FIE), 2014, pp. 2065-2072.

[8] W. Klafki, "Didaktische Analyse als Kern der Unterrichtsvorbereitung," in Auswahl, Grundlegende Aufsätze aus der Zeitschrift Die deutsche Schule Reihe A, vol. 1, Didaktische Analyse, H. Roth and A. Blumenthal, Eds, Hannover: Schroedel, 1964, pp. 5-34.

[9] W. Klafki, Studien zur Bildungstheorie und Didaktik. Weinheim: Beltz, 1965.

[10] W. Klafki, "Didactic analysis as the core of preparation of instruction (Didaktische Analyse als Kern der Unterrichtsvorbereitung)," Journal of Curriculum Studies, vol. 27, no. $1, \quad$ pp. $13-30,1995 . \quad$ http://dx.doi.org/10.1080/00 22027950270103

[11] P. Heimann, G. Otto, and W. Schulz, Eds, Unterricht: Analyse und Planung. Hannover: Schroedel, 1965.

[12] J. S. Bruner, On knowing: Essays for the left hand, 5th ed. Cambridge Massachusetts, 1969.

[13] K.-H. Arnold, "Didactics, Didactic Models and Learning," in Encyclopedia of the Sciences of Learning, N. M. Seel, Ed.: Springer US, 2012, pp. 986-990.

[14] W. Klafki, Neue Studien zur Bildungstheorie und Didaktik: Beiträge zur kritisch-konstruktiven Didaktik. Weinheim: Beltz, 1985.

[15] W. Jank and H. Meyer, Didaktische Modelle, 7th ed. Berlin: Cornelsen Scriptor, 2005.

[16] W. Schulz, "Ein Hamburger Modell in der Unterrichtsplanung: Seine Funktionen in der Alltagspraxis," in Didaktische Modelle und Unterrichtsplanung, B. Adl-Amini and R. Künzli, Eds, München: Juventa, 1980, pp. 49-87.

[17] F. W. Kron, Grundwissen Didaktik, 5th ed. München, Basel: E. Reinhardt, 2008.

[18] W. Klafki, Neue Studien zur Bildungstheorie und Didaktik: Zeitgemäße Allgemeinbildung und kritisch-konstruktive Didaktik, 4th ed. Weinheim: Beltz, 1994.

[19] J. Reischmann, Weiterbildungs-Evaluation: Lernerfolge messbar machen. Neuwied: Luchterhand, 2003.

[20] F. E. Weinert, "Concept of competence: A conceptual clarification," in Defining and selecting key competencies, D. S. 
Rychen and L. H. Salganik, Eds, Seattle: Hogrefe \& Huber, 2001, pp. $45-65$.

[21] J. Hartig, "Kompetenzerfassung von Bildungsprozessen," in Bildungsforschung, vol. 26, Kompetenzerfassung in pädagogischen Handlungsfeldern - Theorien, Konzepte und Methoden, N. Jude, J. Hartig, and E. Klieme, Eds, Bonn, Berlin: Bundesministerium für Bildung und Forschung (BMBF), 2008, pp. 15-25.

[22] Y. Sedelmaier and D. Landes, "SWEBOS - The Software Engineering Body of Skills," International Journal of Engineering Pedagogy (iJEP), vol. 5, no. 1, pp. 12-19, http://onlinejournals.org/index.php/i-jep/article/view/4047, 2015. http://dx.doi.org/10.3991/ijep.v5i1.4047

[23] U. Holm, Teilnehmerorientierung als didaktisches Prinzip der Erwachsenenbildung - aktuelle Bedeutungsfacetten. Available: $\mathrm{http}: / /$ www.die-bonn.de/doks/2012-teilnehmerorientierung-01.pdf (2014, May. 31).

[24] D. E. Hunt, "Lehreranpassung: 'Reading' und 'Flexing'," in Sensibilisierung für Lehrverhalten, A. Claude, Ed, Frankfurt (Main): Pädagogische Arbeitsstelle des Deutschen Volkshochschul-Verbandes, 1986, pp. 9-18.

[25] H. Orth, Schlüsselqualifikationen an deutschen Hochschulen: Konzepte, Standpunkte und Perspektiven. Bielefeld: UVW, Webler, 1999.

[26] L. Reetz, "Zum Zusammenhang von Schlüsselqualifikationen Kompetenzen - Bildung," Aus Politik und Zeitgeschichte. Beilage zur Wochenzeitung Das Parlament, no. 37, pp. 13-20, http://www.sowi-

online.de/reader/berufsorientierung/reetz_lothar_1999_zum_zusa mmenhang_von schluesselqualifikationen_kompetenzen bildung. html, 1999.

[27] D. Schneckenberg, Educating Tomorrow's Knowledge Workers: The Concept of ECompetence and Its Application in International Higher Education: Eburon, 2008.

[28] M. Wagenschein, Verstehen lehren. Weinheim: Beltz, 1968.

[29] H. Siebert, Didaktisches Handeln in der Erwachsenenbildung: Didaktik aus konstruktivistischer Sicht, 2nd ed. Neuwied, Kriftel, Berlin: Luchterhand, 1997.

[30] J. R. Savery, "Overview of Problem-based Learning: Definitions and Distinctions," Interdisciplinary Journal of Problem-based Learning, vol. 1, no. 1, 2006.
[31] P. Figas, S. Knörl, S. Mörtlbauer, Y. Sedelmaier, and I. SchrollDecker, "Developing Software Engineering Education as a Didactical Discipline in its own right," in 1st European Conference Software Engineering Education (ECSEE), Aachen: Shaker, 2014, pp. 1-15.

\section{AUTHORS}

Y. Sedelmaier holds a diploma in pedagogy with a major focus on adult learning and continuing education at the University of Bamberg, Germany. After ten years working experience in the educational sector and in quality management she is now academic researcher in the project "Experimental improvement of learning software engineering" (EVELIN) and investigates students and their learning processes. Her research interests are teaching and learning software engineering at universities and software engineering didactics.

D. Landes holds a diploma in informatics from the University of Erlangen-Nuremberg, Germany, and a PhD in economics from the University of Karlsruhe, Germany. After several years in industry, e.g. with Daimler Research, he became a full professor of software engineering and database systems at the University of Applied Sciences, Coburg, Germany. His research interests are in requirements engineering, software engineering education, and data mining. He (co-)authored around 50 papers in books, journals, and conferences in these areas. Since 2012 he is heading the research project EVELIN.

The research project EVELIN is funded by the German Ministry of Education and Research (Bundesministerium für Bildung und Forschung) under grant no. 01PL12022A. This article is an extended and modified version of a paper presented at IEEE Global Engineering Education Conference (EDUCON2015), held 18. - 20 March 2015, in Tallinn, Estonia. Submitted 28 April 2015. Published as resubmitted by the authors 25 June 2015. 